\title{
A PARAMETER ESTIMATION ALGORITHM FOR INDUCTION MACHINES USING ARTIFICIAL BEE COLONY (ABC) OPTIMIZATION
}

\author{
M. Aminu \\ Dept. of Electrical Engineering, Modibbo Adama Univ. of TeChnology Yola, Adamawa State, Nigeria
} E-mail address: aminumhd@gmail.com

\begin{abstract}
Conventionally, parameters of the Induction Motor (IM) are determined using the standard noload and locked rotor test. Performing the no-load test is simple and involved running the machine uncoupled to a load, while measuring the power, voltage, current and shaft speed at different voltage test points. On the other hand, the locked rotor test requires full control of the rotor mechanically in the locked condition before measurements are taken. This paper presents a method for estimating the parameters of IMs without the need for the no-load and locked rotor tests. The method is based on optimization approach using a relatively new swarm based algorithm called the Artificial Bee Colony (ABC) optimization. Two different equivalent circuits are implemented for the parameter estimation scheme; one with parallel and the other with series magnetization circuit. Parameters of a standard $7.5 \mathrm{~kW}$ IM are estimated using the measured and estimated stator current, input and output power and the power factor. Based on the experimental results obtained, the optimization method using the ABC algorithm gave accurate estimates of the IM parameters when compared to the reference parameters determined using the IEEE standard 112-2004. The maximum errors of $-13.730 \%$ and $2.249 \%$ are obtained for the parallel and series equivalent circuits respectively.
\end{abstract}

Keywords: Inductions Machines, Parameter Estimation, Artificial Bee Colony, Magnetization Circuit, Optimization Algorithm

\section{INTRODUCTION}

Induction machines are by far the most widely used machines constituting about $80 \%$ of the total number of machines used in industry $[1,2]$. This is mainly due to their low cost, reliability, robustness and low maintenance cost when compared to other types of machines. In high performance electric drive systems such as the Field Oriented Control (FOC) or Direct Torque Control (DTC), accurate parameter estimation is needed to guarantee good controller response and overall performance [3]. Over the past few decades, considerable attention has been given in developing new methods for IM parameter estimation.

Conventionally, the IM equivalent circuit parameters are determined using the standard no-load and locked rotor tests. These two tests however represent the extremes of the machine operation, and therefore do not correspond to the normal operating conditions. Consequently, alternative methods have been considered in literature. A review of the major parameter estimation techniques for IMs can be found in [3]. Generally, the methods can be classified into two major groups, namely: signal injection methods and system identification methods. Signal injection methods are usually performed at standstill with the motor excited using a dc or ac signal and parameters determined based on the resulting response. Several studies using signal injection method are reported [4-6]. However, the major drawback of this method is the problem of torque ripples due to the injected signal [7]. System identification methods can be based on steady state measurements [8 - 12] or transient measurements $[13,14]$. Steady state methods use simplified motor models to solve the parameter estimation problem

\footnotetext{
*Author tel: $+234-803-692-2600$
} 
but require multiple tests measurements at different loading conditions.

Optimization techniques that are inspired by the phenomenon of natural evolution and Swarm Intelligence (SI) have been applied for IM parameter estimation [15-17]. These methods rely only on measurements of the motor terminal voltages and currents under steady state operation. Thus, the noload and locked rotor test are avoided making them suitable for field or in-service applications. Generally, optimization methods are based on error minimization criterion. In this paper, the error function for optimization is defined by the percentage difference between the measured (experimental) and the estimated stator current, input and output power and the power factor. The optimization problem is then solved using the $A B C$ optimization algorithm.

\subsection{Steady State Model of an Induction Machine}

The stator and rotor voltage equations of a squirrel cage IM under a balanced sinusoidal supply and in the steady state operating condition as presented in [18] is given by:

$$
\begin{gathered}
\bar{v}_{s d q}=r_{s} \bar{l}_{s d q}+j \omega_{s y n} \bar{\lambda}_{s d q} \\
0=\frac{r_{r}}{s} \bar{l}_{r d q}+j \omega_{s y n} \bar{\lambda}_{r d q}
\end{gathered}
$$

Where $s$ is the slip. Substituting the flux linkage space vectors in (1) and (2) gives:

$$
\begin{gathered}
\bar{v}_{s d q}=r_{s} \bar{l}_{s d q}+j x_{l s} \bar{l}_{s d q}+j x_{m}\left(\bar{l}_{s d q}+\bar{l}_{r d q}\right) \\
0=\frac{r_{r}}{s} \bar{l}_{r d q}+j x_{l r} \bar{l}_{r d q}+j x_{m}\left(\bar{l}_{s d q}+\bar{l}_{r d q}\right)
\end{gathered}
$$

The space vector equations (3) and (4) corresponds to the following phasor equations.

$$
\begin{aligned}
v_{s} & =r_{s} I_{s}+j x_{l s} I_{s}+j x_{m}\left(I_{s}+I_{r}\right) \\
0 & =r_{r} I_{r}+j x_{l r} I_{r}+j x_{m}\left(I_{s}+I_{r}\right)
\end{aligned}
$$

Combining (5) and (6) results in the per-phase equivalent circuit of an IM as shown in Fig. 1.

The resistances $r_{f e}$ and $r_{s t}$ are added to the equivalent circuit to account for the core loss and the stray load loss in the machine. The value of $r_{s t}$ can be determined according to IEEE standard 112 [19] using the equation:

$$
r_{s t}=0.018 r_{r} \frac{\left(1-s_{f l}\right)}{s_{f l}}
$$

Where $s_{f l}$ is the slip at full-load.

The parameters associated with the equivalent circuit are the resistance and leakage reactance of the stator and rotor, the core loss resistance and magnetization reactance. Detail procedures for obtaining these parameters are presented in the next sections.

\subsection{Parameter Estimation Using ABC Algorithm} The parameter estimation method uses the steady state equivalent circuit of an IM to derive an objective function for optimization. In most conventional T-models, the core loss resistance is omitted for simplicity. However, applications such as efficiency estimation or the design of highperformance electric drive systems, the core loss is crucial and therefore must be considered [20]. In this paper two equivalent circuits are used: one with a parallel and the other with a series core loss representation as illustrated in Fig. 1.

\subsubsection{Objective Function Formulation}

The goal of the optimization is to search for the motor parameters by minimizing the error between the measured and estimated quantities such as the stator currents, input power, output power and power factor using experimental and computer simulation data. In order to minimize the number of unknown variables for the optimization algorithm, the resistance of the stator winding $r_{s}$ can be obtained through direct measurements across two terminals of the stator windings [19].

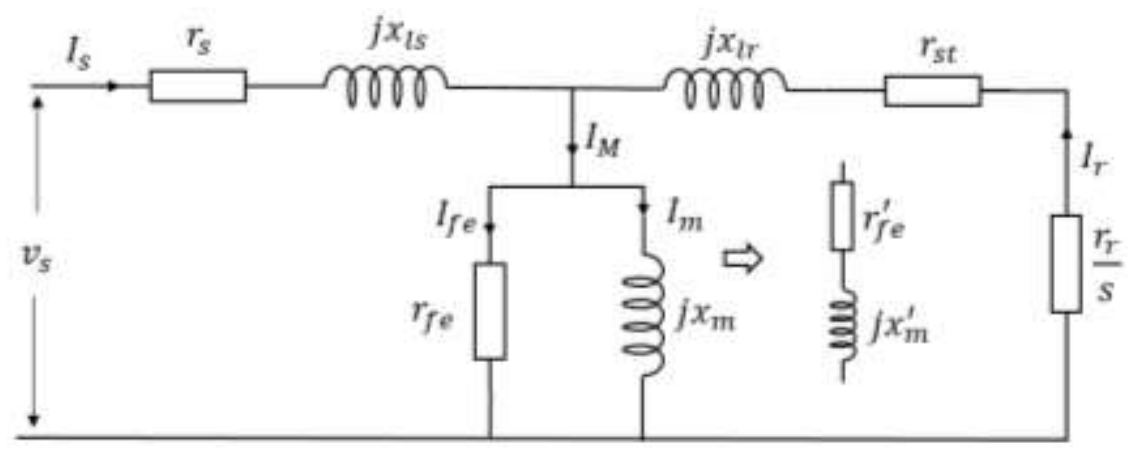

Fig. 1: Equivalent circuit of an Induction Motor 
For a star connected machine, the stator resistance is given by:

$$
r_{s}=0.5 r_{\text {total }}
$$

Where $r_{\text {total }}$ is the resistance measured across the two stator terminals.

The ratio of stator to rotor reactance can also be used to determine the stator reactance based on the NEMA design class of the machine [21] as shown in Table 1.

Table 1: Ratio of $x_{s} / x_{r}$ based on NEMA design class

\begin{tabular}{cc}
\hline$x_{s} / x_{r}$ & NEMA Design class \\
\hline$x_{s} / x_{r}=1.00$ & $\mathrm{~A}, \mathrm{D}$ and wound rotor motors \\
$x_{s} / x_{r}=0.67$ & $\mathrm{~B}$ \\
$x_{s} / x_{r}=0.43$ & $\mathrm{C}$ \\
\hline
\end{tabular}

With the stator resistance and reactance determined, only four variables are to be searched using the optimization techniques. These parameters are the rotor resistance $\left(r_{r}\right)$, the core loss resistance $\left(r_{f e}\right)$, the rotor leakage reactance $\left(x_{l r}\right)$ and the magnetization reactance $\left(x_{m}\right)$.

Since values of resistances are affected by temperature changes, the stator and rotor resistances are to be corrected according to IEEE Standard 112-2004 [19] using (9):

$$
R_{t}=R_{m}\left(\frac{T_{t}+C}{T_{m}+C}\right)
$$

Where $R_{t}$ and $R_{m}$ are the resistance at a specified temperature $T_{t}$ and the measured resistance at $T_{m}$ respectively. $C$ is the zero-resistance temperature constant $(C=234.5$ for copper and $C=224.1$ for aluminum). Thus, the corrected resistances for the stator and rotor are:

$$
\begin{gathered}
r_{s-c}=r_{\text {stator }}\left(\frac{T_{t}+C}{T_{m}+C}\right) \\
r_{r-c}=r_{\text {rotor }}\left(\frac{T_{t}+C}{T_{m}+C}\right)
\end{gathered}
$$

The following equations can be derived based on the equivalent circuit shown in Fig.1:

$$
\begin{gathered}
Y_{s}=\frac{1}{r_{s-c}+j x_{s}} \\
Y_{r}=\frac{1}{\frac{r_{r}}{s}+r_{s t}+j x_{r}}
\end{gathered}
$$

For parallel magnetizing circuit:

$$
\begin{array}{r}
Y_{m}=\frac{1}{r_{f e}}-\frac{j}{x_{m}} \\
I_{s-e s t}=\left|\frac{v_{s} Y_{s}\left(Y_{r}+Y_{m}\right)}{Y_{s}+Y_{r}+Y_{m}}\right|
\end{array}
$$

$$
\begin{gathered}
I_{m}=\left|\frac{v_{s} Y_{s}}{r_{f e}\left(Y_{s}+Y_{r}+Y_{m}\right)}\right| \\
p f_{\text {est }}=\frac{\operatorname{Real}\left(I_{s}\right)}{I_{s-e s t}} \\
I_{r}=\left|\frac{v_{s} Y_{S} Y_{r}}{Y_{s}+Y_{r}+Y_{m}}\right| \\
P_{\text {input-est }}=3\left(I_{s}^{2} r_{s-c}+I_{r}^{2}\left(\frac{r_{r-c}}{s}+r_{s t}\right)+I_{m}^{2} r_{f e}\right) \\
P_{\text {output-est }}=3 r_{r}^{2} r_{r-c}\left(\frac{1-s}{s}\right)
\end{gathered}
$$

The parallel magnetization branch shown in Fig. 1 can be transformed into a series connection [22] and the series resistance $\left(r_{m}^{\prime}\right)$ and reactance $\left(x_{m}^{\prime}\right)$ expressed as:

$$
\begin{gathered}
r_{f e}^{\prime}=\frac{x_{m}^{2} r_{f e}}{r_{f e}^{2}+x_{m}^{2}} \\
x_{m}^{\prime}=\frac{r_{f e}^{2} x_{m}}{r_{f e}^{2}+x_{m}^{2}}
\end{gathered}
$$

Thus, the series admittance is:

$$
Y_{m}^{\prime}=\frac{1}{r_{f e}^{\prime}+j x_{m}^{\prime}}
$$

$Y_{m}^{\prime}$ as presented in equation (23), is used as the magnetization admittance in (15), (16) and (18) for the series magnetization circuit.

The goal of optimization is to minimize the error between the measured and estimated quantities defined by the following functions:

$$
\begin{gathered}
f_{1}=\left(\frac{I_{s-e s t}-I_{s}}{I_{s}}\right) \times 100 \\
f_{2}=\left(\frac{P_{\text {input }- \text { est }}-P_{\text {input }}}{P_{\text {input }}}\right) \times 100 \\
f_{3}=\left(\frac{p f_{\text {est }}-p f}{p f}\right) \times 100 \\
f_{4}=\left(\frac{P_{\text {output }- \text { est }}-P_{\text {output }}}{P_{\text {output }}}\right) \times 100
\end{gathered}
$$

The objective function to be minimized is therefore as given in (28):

$$
f_{o b j}=\sum_{i=1}^{n}\left(\sum_{j=1}^{m} f_{j}^{2}\right)_{i}
$$

subject to the inequality parameter vector constraint:

$$
P(\theta)_{-\min } \leq P(\theta) \leq P(\theta)_{-\max }
$$

Where $n$ and $m$ are the number of load points and the number of measured data respectively, $\theta=$ $\left[r_{r}, x_{l r}, r_{f e}, x_{m}\right]$ is a vector containing the unknown motor parameters.

\subsection{Abc Optimization Algorithm}

Artificial Bee Colony $(A B C)$ Optimization is one of the new swarm intelligent optimization technique 
developed by Karaboga [23]. ABC algorithm simulates the intelligent foraging behavior of honey bee swarm. Several research works have demonstrated the performance of the $A B C$ algorithm compared to other population-based optimization algorithms [24, 25]. The advantage the $A B C$ algorithm over other population-based algorithms is its simple structure- requiring only few control parameters.

The $A B C$ algorithm consists of three categories of bees: the employed bee, onlooker bee and the scout bee. the employed bee constitutes half of the colony size while the remaining half is the onlooker bee. The number of employed bee is equal to the number of food source, thus there is exactly one employed bee for each food source. Employed bee search for food sources and pass the information to the onlooker bees. An employed bee whose food source is not improved after a number of trails determined by the ABC control parameter called the 'limit' becomes a scout bee and abandoned its initial food source. The position of the food source represents a possible solution to an optimization problem and the nectar amount represents the fitness of the solution. The stages in the $A B C$ algorithm can be explained as follows:

\subsubsection{Initializing the food source}

The initial food sources are produced randomly within the specified boundaries of the optimization constraints. This can be represented by (30).

$$
x_{i, j}=x_{j}^{\text {min }}+\operatorname{rand}(0,1)\left(x_{j}^{\text {max }}-x_{j}^{\text {min }}\right)
$$

Where, $i=0,1,2, \ldots N S / 2, j=1,2,3, \ldots D$. NS is the number of food source and $D$ is the dimension of the problem.

After the initialization, $X_{i, j}$ is subjected to repeated cycles going through the employed, onlooker and scout bee phases until the stopping criteria is achieved.

\subsubsection{Employed Bee Phase}

Each employed bee in the $A B C$ algorithm is assigned to a food source. An employed bee evaluates the fitness (nectar amount) of its food source and search a neighboring food source using (31)

$$
v_{i, j}=x_{i, j}+\phi_{i, j}\left(x_{i, j}-x_{k, j}\right)
$$

$k$ and $\phi_{i, j}$ are randomly selected numbers within the boundaries $0,1,2, \ldots N S / 2$ and -1 to 1 respectively.
After obtaining $v_{i, j}$, a fitness value for a minimization problem $\mathrm{fit}_{i}$ can be assigned to the solution using (32)

$$
f_{i t}=\left\{\begin{array}{lll}
\frac{1}{1+f_{o b j_{i}}} & \text { if } & f_{o b j_{i}} \geq 0 \\
1+a b s\left(f_{o b j_{i}}\right) & \text { if } & f_{o b j_{i}}<0
\end{array}\right.
$$

Where $f_{o b j_{i}}$ is the objective function value of the $i^{t h}$ solution.

A greedy selection is applied between the old solution $X_{i, j}$ and the new $v_{i, j}$ by selecting the better one depending on its fitness value. The employed bee memorizes the new position and forgets the old one, otherwise the previous position is kept in memory. If $X_{i, j}$ cannot be improved, its counter (holding the number of trials) is incremented by 1 , otherwise, the counter is reset to 0 [25]. At the end of the search cycle, the employed bee shares the information of their food source to the onlooker bees. The quality of food source is determined by a probability function $p_{i}$ given by (33):

$$
p_{i}=\frac{f i t_{i}}{\sum_{i=1}^{N S / 2} f i t_{i}}
$$

\subsubsection{Onlooker bee phase}

In this stage, the onlooker bees are enrolled into foraging by the employed bees. The onlookers select a food source based on its probability represented by (33). As in the employed bee phase, the position of food source is modified using (31). The greedy selection is applied and new solution is memorized or the old solution is retained depending on its fitness. If the solution cannot be improved after a number of trials determined by the 'limit', then its counter is incremented by 1 , otherwise, it is reset to 0 . This procedure is repeated until all onlookers are distributed onto the food sources.

\subsubsection{Scout bee phase}

After completing a cycle, the $A B C$ algorithm checks for any exhausted food source to be abandoned. The criteria for determining the food source to be abandoned are based on the trail counter. A food source whose trial counter is greater than the control parameter of the ABC algorithm called the 'limit' is abandoned and replaced with a new one discovered by the scout bee. In the basic $A B C$ algorithm, it is assumed that only one source can be exhausted and only one employed bee can be a scout in each cycle [23]. 


\section{RESULTS AND DISCUSSIONS}

To verify the proposed $A B C$ parameter estimation method, a $7.5 \mathrm{~kW}$ standard efficiency IM with nameplate data given in Table 2 is tested using the experimental setup shown in Fig. 2. The induction machine is coupled to a dynamometer through an inline torque transducer.

The IEEE std 112-2004 impedance test method 1 [19] was performed and the results obtained are shown in Table 3. These results are used as the reference values for comparison with the proposed $A B C$ method.

For the $A B C$ method, a rated temperature test as specified in the IEEE standard 112-2004 is first performed. This test is to allow the machine's temperature to stabilize before taking measurements. The temperature test is followed by the load test. in this test, the machine is subjected to loads at five points approximately spaced between $125 \%$ down to $25 \%$ of the rated load. Readings of the stator current, voltage, shaft speed, electrical and mechanical power and the stator winding temperature are taken at each load point. The results from this test are shown in Table 4.

The power factor is calculated for each load point based on Table 3 using (34)

$$
p f=\frac{P_{\text {elec }}}{\sqrt{3} v_{s} I_{s}}
$$

The data in Table 3 and in addition the power factor for each load point are used as the measured quantities in (24) to (28) to compute the cost function for the $A B C$ optimization algorithm. The code for the $A B C$ optimization was implemented using the Matlab (2014) software package based on the parameter settings shown in Table 5.

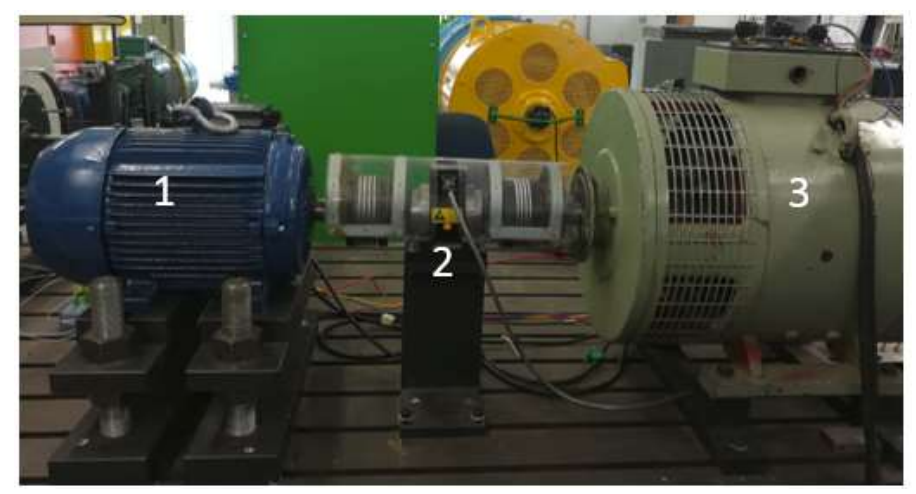

Fig. 2: The experimental test rig (1) Induction machine (2) In-line torque transducer (MEGTROL TM 300 series) (3) Dynamometer (15kW DC machine).

Table 2: Nameplate data of the test motor

\begin{tabular}{cccccccc}
\hline Power & $\boldsymbol{V}_{L L}$ & $\boldsymbol{I}_{\text {Rated }}$ & Freq. & $\boldsymbol{n}_{\text {Rated }}$ & poles & Class & Insl. \\
\hline $7.5 \mathrm{KW}$ & $380 \mathrm{~V}$ & $15.1 \mathrm{~A}$ & $50 \mathrm{~Hz}$ & $1450 \mathrm{rpm}$ & 4 & $\mathrm{~B}$ & $\mathrm{~F}$ \\
\hline
\end{tabular}

Table 3: No-load and block rotor test parameters

\begin{tabular}{lcccccc}
\hline 7.5kW Motor & $r_{s}(\Omega)^{*}$ & $r_{r}(\Omega)$ & $x_{l s}(\Omega)$ & $x_{l r}(\Omega)$ & $x_{m}(\Omega)$ & $r_{f e}(\Omega)$ \\
\hline IEEE std 112 Parallel circuit & 1.900 & 1.310 & 3.497 & 5.220 & 98.500 & 1400.700 \\
IEEE std 112 Series circuit & 1.900 & 1.310 & 3.497 & 5.220 & 98.015 & 6.893 \\
\hline
\end{tabular}

* Stator resistance measured directly

Table 4: Load test results for the $7.5 \mathrm{~kW}$ test motor

\begin{tabular}{ccccccc}
\hline Test point $(\%)$ & $v_{S}(V)$ & $I_{s}(A)$ & $P_{\text {elec }}(W)$ & $P_{\text {mech }}(W)$ & $\omega_{r}(r p m)$ & Temp. $(r p m)$ \\
\hline 125 & 375.68 & 19.08 & 11,123 & 9,213 & 1,425 & 116.17 \\
100 & 376.94 & 15.15 & 8,731 & 7,471 & 1,445 & 124.28 \\
75 & 378.18 & 11.70 & 6,474 & 5,671 & 1,462 & 118.78 \\
50 & 379.40 & 8.66 & 4,236 & 3,817 & 1,476 & 115.68 \\
25 & 380.39 & 6.51 & 2,294 & 1,925 & 1,489 & 108.88 \\
\hline
\end{tabular}


Table 5: The parameter settings for the $A B C$ algorithm

\begin{tabular}{ccccc} 
Food source $(N S)$ & Colony size $(2 * N S)$ & Max. Iterations & Dimension $(D)$ & Limit $(N S * D)$ \\
\hline 50 & 100 & 50 & 4 & 200
\end{tabular}

Figs. 3 a to Fig. $3 g$ shows the convergence of the cost function and the motor parameters using the $A B C$ algorithm for the parallel equivalent circuit. As shown

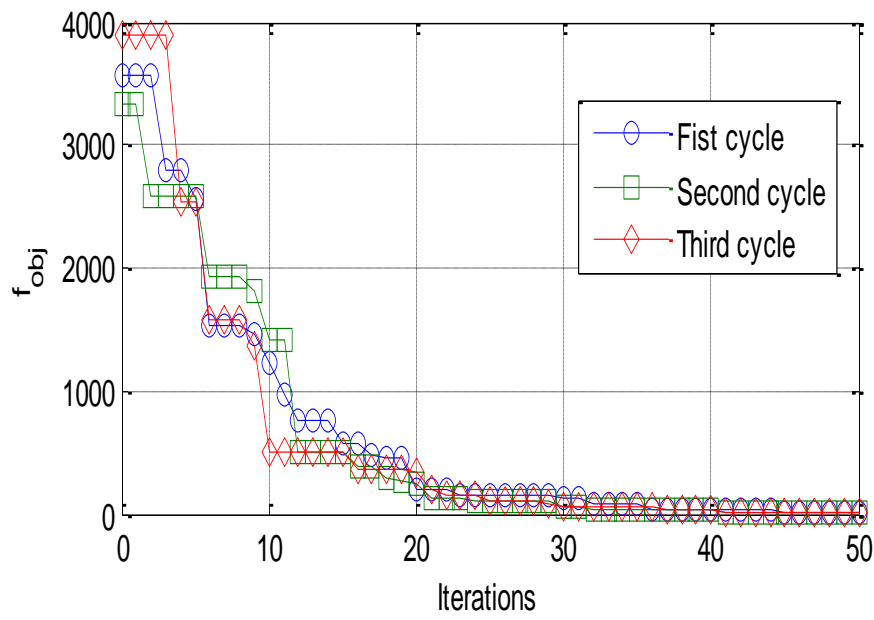

(a)

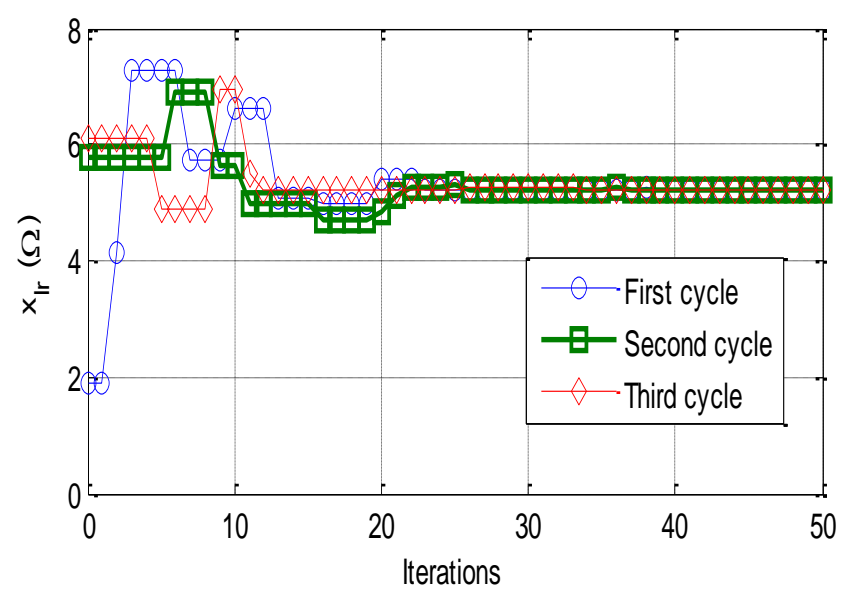

(c)

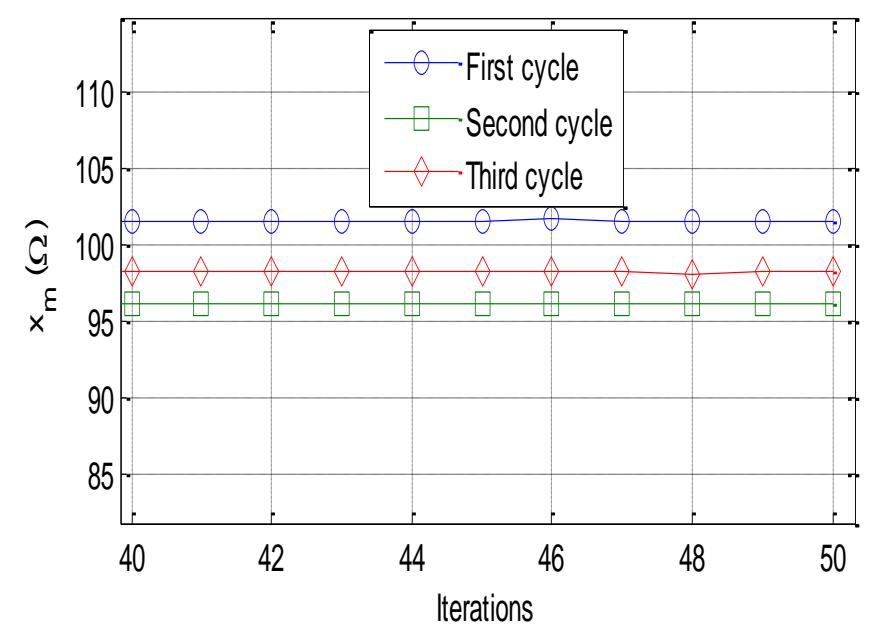

(e) in the figures, the algorithm is run three time with the same input data to test for consistency.

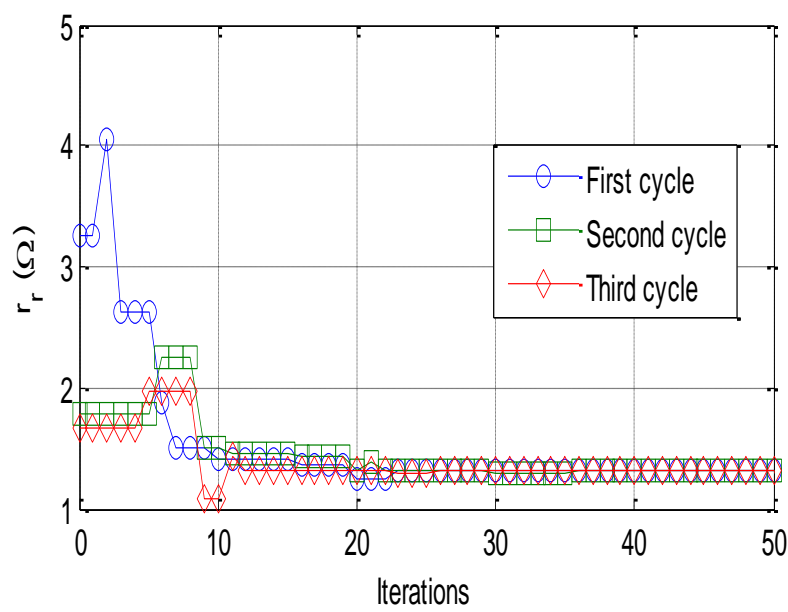

(b)

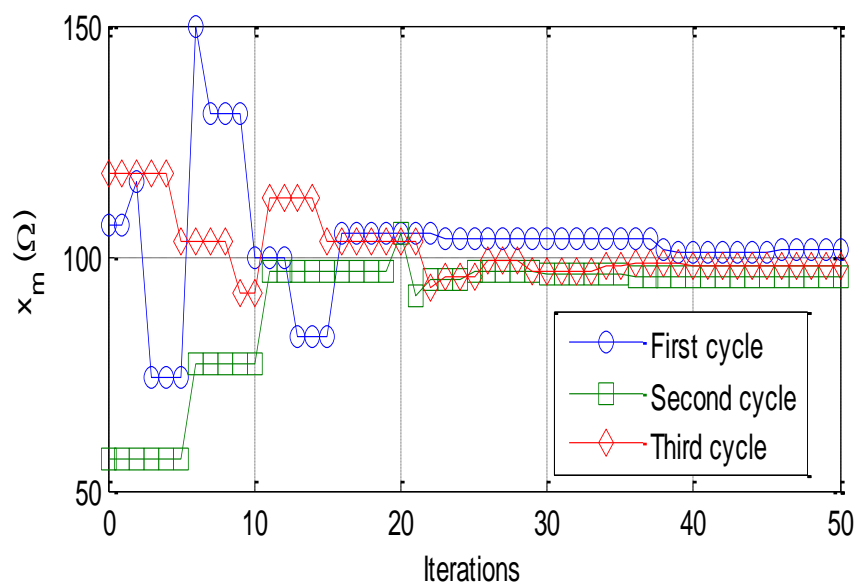

(d)

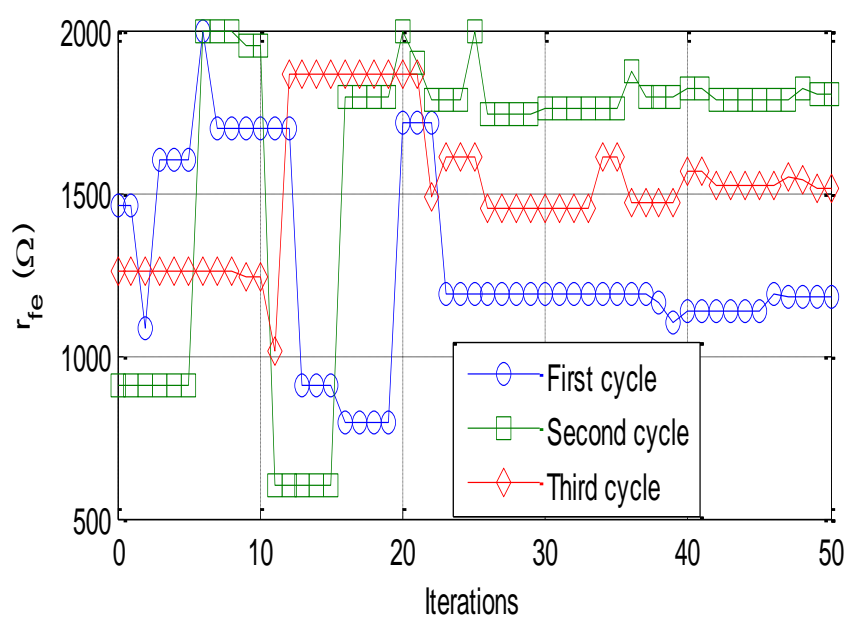

(f) 


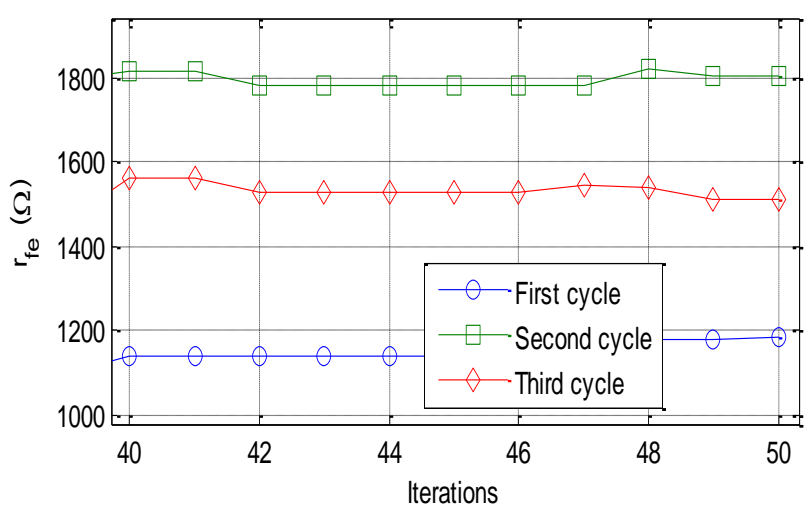

(g)

Fig. 3: Convergence profiles (parallel circuit): (a) Objective function (b) Rotor resistance (c) Rotor leakage reactance (d) Magnetization reactance (e) Magnetization reactance (Zoomed) ( $f$ ) Core loss resistance $(g)$ Core loss resistance (Zoomed)

As can be seen in Fig. 3a, the objective function converges after about 42 iterations for all the three cycles. As shown in Fig. 3b and Fig. 3c, consistent steady values of $1.3084 \Omega$ and $5.2351 \Omega$ are obtained in all three optimization cycles for the rotor resistance and leakage reactance respectively. On the other hand, inconsistent results are obtained for the core loss resistance and magnetization reactance as can be seen in Figs. 3d to Fig. 3g. The disparity can be seen to be more pronounced in the estimation of the core loss resistance as can be observed in the Fig. $3 \mathrm{~g}$. This problem has been observed in [26] and is due to the small impact of the core loss resistance on the stator IM currents.

One way of solving this problem is to use a series instead of the parallel circuit for the magnetization branch. Fig. 4a to Fig. 4e show the results for the series equivalent circuit.

As can be observed, the $A B C$ algorithm was able to tracks the equivalent circuit parameters including the core loss resistance and the magnetization reactance in all the optimization cycles.

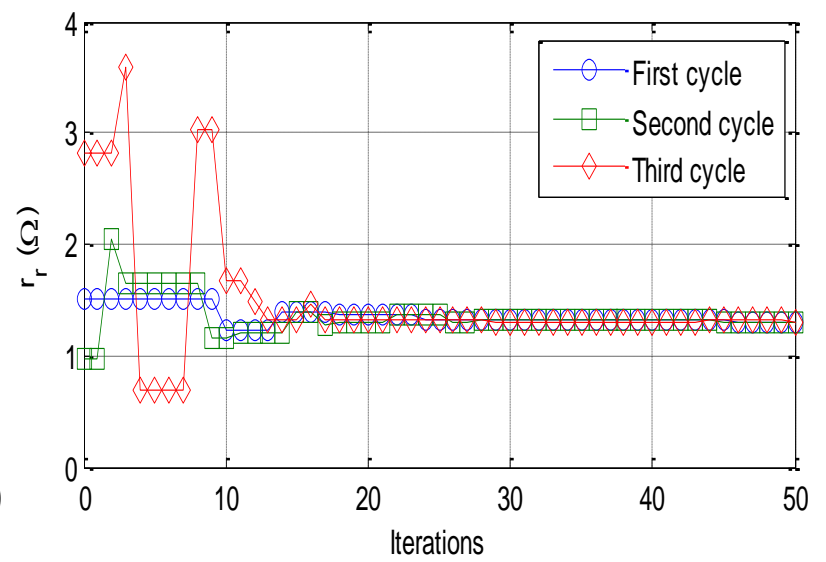

(b)

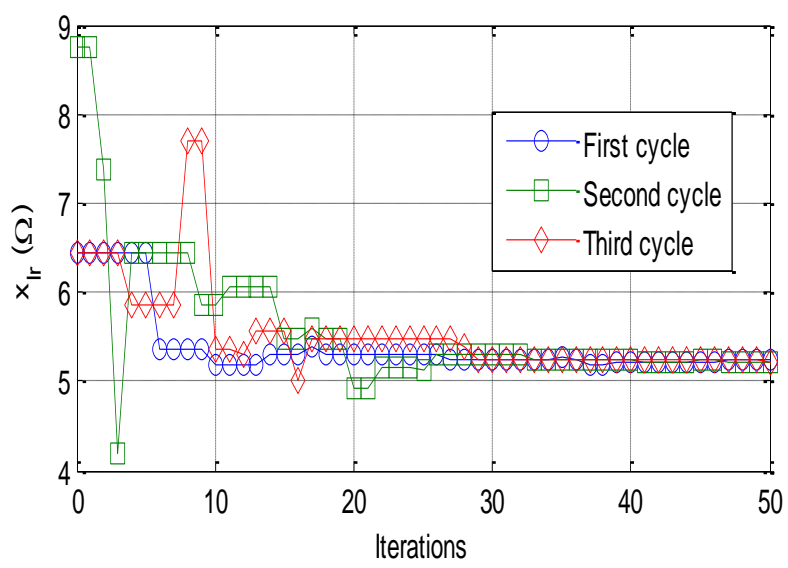

(c)

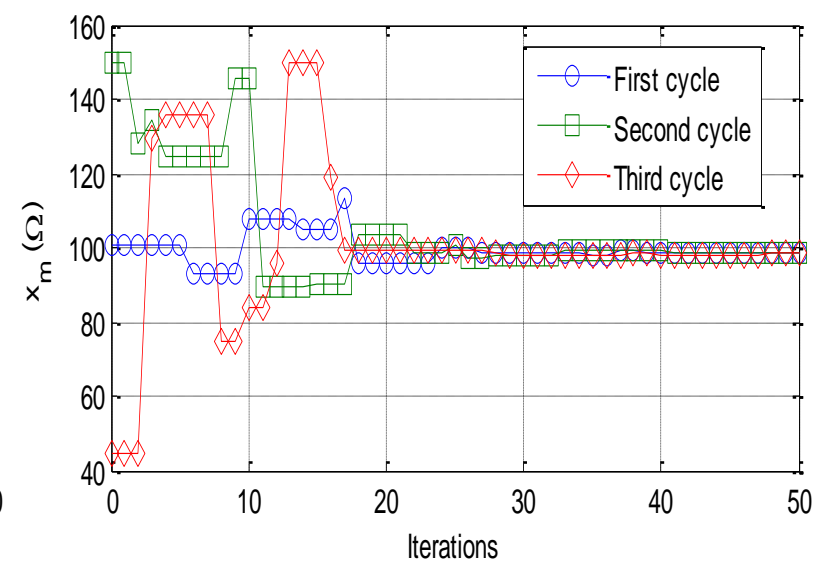

(d) 


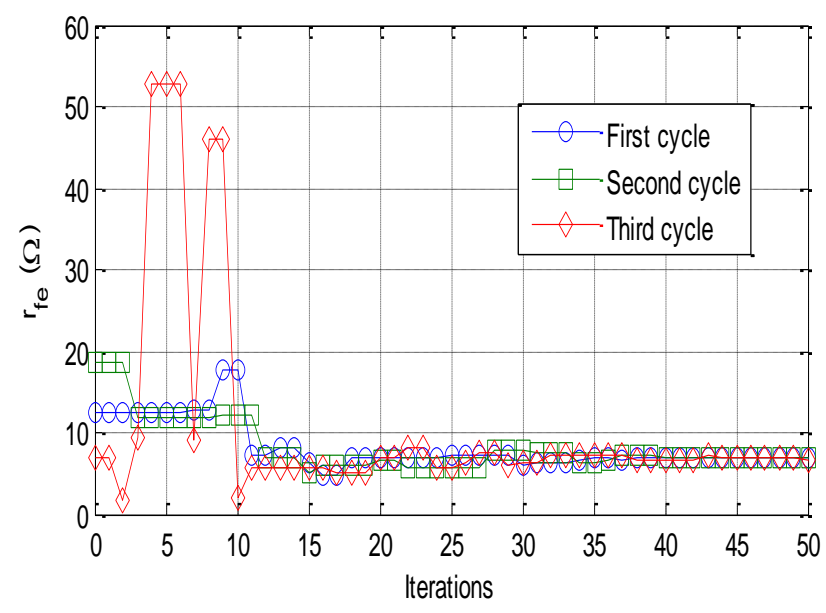

(e)

Fig. 4: Convergence profile (series circuit): (a) objective function (b) Rotor resistance (c) Rotor leakage reactance (d) Magnetization reactance (e) Core loss resistance

Table 6 summarizes the final parameter estimation results for the parallel and series equivalent circuits. The results are the average values for 10 cycles of the $A B C$ algorithm.

Table 6: No-load and block rotor test parameters

\begin{tabular}{ccccc}
\hline 7.5kW Motor & $r_{r}(\Omega)$ & $x_{l r}(\Omega)$ & $x_{m}(\Omega)$ & $r_{f e}(\Omega)$ \\
\hline Parallel & 1.320 & 5.285 & 109.000 & 1593.000 \\
Ref. & 1.310 & 5.220 & 98.500 & 1400.700 \\
Error (\%) & -0.763 & -1.245 & -10.660 & -13.730 \\
Series & 1.309 & 5.233 & 97.948 & 6.738 \\
Ref. & 1.310 & 5.220 & 98.015 & 6.893 \\
Error (\%) & 0.764 & -0.249 & 0.068 & 2.249 \\
\hline
\end{tabular}

From Table 6, it can be observed that accurate parameter estimates are obtained for both the parallel and series equivalent circuits when compared to the reference values. This is because the $A B C$ algorithm as a global optimization method avoids convergence to an undesired local minimum. However, in terms of the percentage error, the series equivalent circuit gives more accurate results when compared to the parallel equivalent circuit.

\section{CONCLUSSION}

In this paper, a simple, yet accurate method for IM parameter estimation is presented. The method relies on external measurements to formulate a distance criterion objection function that defined the relationship between the measured data and their corresponding estimates. The estimated quantities are defined based on two different arrangements of the magnetization branch in the IM equivalent circuit. Based on the experimental results obtained, the $A B C$ algorithm was able to track the machine parameters for both the parallel and series equivalent circuits with acceptable level of accuracy. However, the results show that the series equivalent circuit implementation gave more accuracy in terms of the percentage error and repeatability.

\section{REFERENCES}

[1] T. Fleiter, W. Eichhammer, and K. J. Schleih, "Energy efficiency in electric motor systems: Technical potentials and policy approaches for developing countries", United Nations Ind. Organ. Rep., pp. 1-34, 2011.

[2] P. Waide and C. U. Brunner, "Energy-Efficiency Policy Opportunities for Electric Motor-Driven Systems", Int. Energy Agency, Energy Effic. Ser. Rep., pp. 1-132, 2011.

[3] H. A. Toliyat, E. Levi, M Raina., "A Review of RFO Induction Motor Parameter Estimation Techniques", IEEE Trans. on Energy Convers, vol. 18, no. 2, pp. 271-283, 2003.

[4] A. Bechouche, H. Sediki, D. O. Abdeslam, and S. Haddad, "A Novel Method for Identifying Parameters of Induction Motors at Standstill Using ADALINE", IEEE Trans. on Energy Convers, vol. 27, no. 1, pp. 105-116, 2012.

[5] M. Carraro and M. Zigliotto, "Automatic Parameter Identification of Inverter-Fed Induction Motors at Standstill", IEEE Trans. on Ind. Elect., vol. 61, no. 9, pp. 4605-4613, 2014.

[6] P. Castaldi and A Tilli, "Parameter Estimation of Induction Motor at Standstill with Magnetic Flux Monitoring", IEEE Trans. on Cont. Sys. Tech. vol. 13, no. 3, pp. 386-400, 2005.

[7] B. Lu, T. G. Habetler, and R. G. Harley, "A Nonintrusive and In-Service Motor-Efficiency Estimation Method Using Air-Gap Torque With Considerations of Condition Monitoring", IEEE Trans. on Ind. Applications, vol. 44, no. 6, pp. 1666-1674, 2008.

[8] Reed D. M., Hofmann H. F., and Sun J., (2016). Offline Identification of Induction Machine Parameters With Core Loss Estimation Using the Stator Current Locus, IEEE Trans. on Energy Convers, vol. 31, no. 4, pp. 1549-1558.

[9] A. Marcus and N. Lima, "Nonlinear parameter 
estimation of steady-state induction machine models", IEEE Trans. Ind. Electron., vol. 44, no. 3, pp. 390-397, 1997.

[10] B. Abdelhadi, A. Benoudjit, and N. Nait-Said, "Application of genetic algorithm with a novel adaptive scheme for the identification of induction machine parameters", IEEE Trans. Energy Convers., vol. 20, no. 2, pp. 284-291, 2005.

[11] M. Cirrincione, M. Pucci, G. Cirrincione, and G. A. Capolino, "Constrained minimization for parameter estimation of induction motors in saturated and unsaturated conditions", IEEE Trans. Ind. Electron., vol. 52, no. 5, pp. 13911402, 2005.

[12] M. H. Haque, "Determination of NEMA design induction motor parameters from manufacturer data", IEEE Trans. Energy Convers., vol. 23, no. 4, pp. 997-1004, 2008.

[13] S. R. Shaw and S. B. Leeb, "Identification of induction motor parameters from transient stator current measurements", IEEE Trans. Ind. Electron., vol. 46, no. 1, pp. 139-149, 1999.

[14] M. Ranta and M. Hinkkanen, "Online identification of parameters defining the saturation characteristics of induction machines", IEEE Trans. Ind. Appl., vol. 49, no. 5, pp. 21362145, 2013.

[15] M. Al-badri, P. Pillay, and P. Angers, "A Novel Algorithm for Estimating Refurbished ThreePhase Induction Motors Efficiency", IEEE Trans. Energy Convers., vol. 30, no. 2, pp. 615-625, 2015.

[16] A. I. Kanakoglu, A. G. Yetgin, H. Temurtas, and $M$. Turan, "Induction motor parameter estimation using metaheuristic methods", Turkish Journal of Electrical Engineering \& Computer Sciences, Vol., 22, pp. 1177-1192, 2014

[17] J. Seesak and L. Panthep, "Parameter Estimation of Three-Phase Induction Motor by using Genetic Algorithm", Journal of Electrical Engineering \& Technology Vol. 4, No. 3, pp. 360364, 2009.

[18] N. Mohan, "Advanced Electric Drives: Analysis, Control, and Modelling using MATLAB/SIMULINK", John Wiley \& Sons Inc., New Jersey (Chapters 2 \& 3), 2012.

[19] IEEE Standard 112, "IEEE Standard Test Procedure for Polyphase Induction motors and Generators", 2004

[20] J. Jung, and K. Nam, "A Vector Control Scheme for EV Induction Motors with a Series Iron Loss Model", IEEE Trans. Ind. Electron., vol. 45, no. 4, pp. 617-624, 1998.

[21] National Electrical Manufacturers Association (NEMA), NEMA MG 1-2016, for Motors and Gnerators, 2006.

[22] P. Pillay, V. Levin, P. Otaduy, and J. Kueck, "In-situ induction motor efficiency determination using the genetic algorithm", IEEE Trans. Energy Convers., vol. 13, no. 4, pp. 326-333, 1998.

[23] D. Karaboga, "An idea based on honey bee swarm for numerical optimization. Technical Report-TR06", Erciyes University, Engineering Faculty, Computer Engineering Department, 2005.

[24] D. Karaboga and B. Akay, "A comparative study of Artificial Bee Colony algorithm", Appl. Math. Comput., vol. 214 , no. 1 , pp. 108-132, 2009.

[25] B. Akay and D. Karaboga, "A modified Artificial Bee Colony algorithm for real-parameter optimization", Inf. Sci. (Ny)., vol. 192, pp. 120142, 2012.

[26] B. Lu, W. Cao, I. French, K. J. Bradley, and T. G. Habetler, "Non-intrusive efficiency determination of in-service induction motors using genetic algorithm and air-gap torque methods", Conf. Rec. - IAS Annu. Meet. (IEEE Ind. Appl. Soc.), pp. 1186-1192, 2007. 